\title{
New species of Hymenoepimecis Viereck (Hymenoptera, Ichneumonidae, Pimplinae) from Brazilian Atlantic forest
}

\author{
Ana Paula da Silva Loffredo ${ }^{1} \&$ Angélica M. Penteado-Dias ${ }^{2}$
}

\begin{abstract}
${ }^{1}$ Programa de Pós-graduação em Ecologia e Recursos Naturais. Universidade Federal de São Carlos, Rodovia Washington Luiz, km 235, Monjolinho, 13565-905 São Carlos-SP, Brasil. ap_loffredo@yahoo.com.br

${ }^{2}$ Departamento de Ecologia e Biologia Evolutiva, Universidade Federal de São Carlos, Rodovia Washington Luiz, km 235, Monjolinho, 13565-905 São Carlos-SP, Brasil. angelica@ufscar.br
\end{abstract}

\begin{abstract}
New species of Hymenoepimecis Viereck (Hymenoptera, Ichneumonidae, Pimplinae) from Brazilian Atlantic forest. In this study three new Brazilian species of Hymenoepimecis are described and illustrated. The specimens were collected using sweeping the vegetation and Malaise traps in areas of Atlantic forest in southeastern Brazil. The material described is figured with digital images.
\end{abstract}

KEYWORDS. Atlantic rain forest; biodiversity; parasitoids; taxonomy.

RESUMO. Novas espécies de Hymenoepimecis Viereck (Hymenoptera, Ichneumonidae, Pimplinae) da Mata Atlântica brasileira. Neste estudo são descritas e ilustradas três novas espécies brasileiras de Hymenoepimecis com espécimes coletados por meio de "varredura" da vegetação e armadilhas Malaise em áreas de mata Atlântica no sudeste do Brasil.

PALAVRAS-CHAVE. Mata Atlântica; biodiversidade; parasitóides; taxonomia.

The Pimplinae is the most biologically diverse group of Ichneumonidae and it is associated with a wide range of hosts (Gauld 1991). Hymenoepimecis Viereck, 1912, includes nine species most of them known from Neotropical region, two from Brazil. It belongs to the Polysphincta genus-group (Gauld \& Dubois 2006) and can be characterized by presence of a pocket-like structure on the pronotum. This genus includes koinobiont parasitoids of adult spiders with some species from tropical America humid forest waiting for description (Gauld 1991).

Three new Hymenoepimecis species from Brazil are described in this study. The subfamily Pimplinae and the genus Hymenoepimecis were recognized using Gauld (1991) and Gauld \& Dubois (2006).

The material comes from State of São Paulo, Brazil, Campos

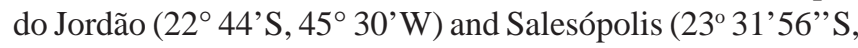
$\left.45^{\circ} 50^{\prime} 47^{\prime \prime} \mathrm{W}\right)$. The material was collected sweeping the vegetation and using Malaise traps from 700 to $1000 \mathrm{~m}$ of altitude in Atlantic forest areas. The specimens are deposited at the collection of the Departamento de Ecologia e Biologia Evolutiva da Universidade Federal de São Carlos, SP, Brazil (DCBU).

\section{Hymenoepimecis silvanae sp. nov.} (Figs. 1-4)

Material. - Holotype, ㅇ (DCBU), "[Brazil] State of São Paulo, Campos do Jordão, 23. XI to 10.XII.2001, $700 \mathrm{~m}$ altitude, Malaise trap, S. A. G. Gomes col."

Holotype, o , ( Fig. 1). Length: $15 \mathrm{~mm}$. Fore wing: $12 \mathrm{~mm}$. Antenna with 42 antennomeres, lower face smooth elongate
(Fig. 2), $0.7 \mathrm{x}$ as broad as high, slightly convex with two shallow furrows from median area to up; presence of small tubercle between base of scapes; head with gena long; posterior ocellus separated from eye by $1.2 \mathrm{x}$ its own maximum diameter. Pronotum long, distance from tegula to head about $0.8 \mathrm{x}$ distance from tegula to hind margin of propodeum; scutellum convex; mesopleurum smooth and polished with anterodorsal and posteroventral parts with fine and scattered hairs; propodeum smooth and polished with scattered hairs, submetapleural carina absent. Fore wing with cu-a more or less interstitial to base of Rs \& M, 2 rs-m about $0.7 \mathrm{x}$ as long as abcissa of $\mathrm{M}$ between $2 \mathrm{rs}-\mathrm{m}$ and $2 \mathrm{~m}-\mathrm{cu}$, vein $3 \mathrm{r}-\mathrm{s}$ absent, hind wing with abscissa of $\mathrm{Cu} 1$ meeting cu-a equidistant between $\mathrm{M}$ and 1A (Fig. 3). Hind leg with tibia plus tarsus 0.6x fore wing length. Metasoma moderately slender, tergite I 1.6x as long as the posterior margin broad with convergent lateral carinae present only anteriorly; sternite I with slight rounded swelling posteriorly (Fig. 4), tergites II-VI centrally smooth and with scattered hairs around, tergite II $2.4 \mathrm{x}$ and tergite III about $1.2 \mathrm{x}$ as long as posteriorly broad. Ovipositor $2.0 \mathrm{x}$ as long as hind tibia.

Head black, apical margin of clypeus testaceous, mandible, except tip, and palpi pale yellow, antenna black. Mesosoma and metasoma mostly orange brown. Pronotum infuscated anteriorly, metasoma with tergites II-IV with posterior margin darker. Sternite I smooth, orange brown; II - VI light brown and coreaceous. Ovipositor brownish, sheaths black. Anterior two pairs of legs yellow, hind leg orange brown with coxa posteriorly, tibia posteriorly and tarsi brownish, tibial spurs yellow. Wings hyaline yellowish; fore wing apically and centrally, between nervelus and junction of radius with stigma 
with fascia infumate, pterostigma almost all yellow, anteriorly blackish.

Etymology: This species honors Silvana Angélica Gama Gomes who collected the specimens of Pimplinae to this study.

Hymenoepimecis silvanae sp. nov. resembles H. heteropus (Kriechbaumer, 1890). Both species have the fore wing bifasciate, differing in metasoma color: mostly orange brown in H. silvanae sp. nov. and mostly black in H. heteropus. The hind leg is black in H. heteropus; in H. silvanae sp. nov. the hind leg is mostly orange brown.

Male: Unknown

\section{Hymenoepimecis jordanensis sp.nov. (Figs. 5-9)}

Material. - Holotype, 우 (DCBU), “[Brazil] State of São Paulo Campos do Jordão, 29.III to 14.IV.2002, $900 \mathrm{~m}$ altitude, S. A. G. Gomes col." Paratypes, 1 i (DCBU), "[Brazil] SP, Campos do Jordão, 27.IX to 12.X.2002, $900 \mathrm{~m}$ altitude, Malaise trap, S. A. G. Gomes col. 1 i (DCBU)", "[Brazil] SP, Campos do Jordão, 27.IX to 12.X.2002, $1000 \mathrm{~m}$ altitude, Malaise trap, S. A. G. Gomes col. 1 +(DCBU), "[Brazil] SP, Salesópolis, Estação Biológica de Boracéia, 5. IV.2001, sweeping, S. T. P. Amarante col.

Holotype, ㅇ, (Fig. 5). Length: $9 \mathrm{~mm}$. Fore wing: $6 \mathrm{~mm}$. Antenna with 33 antennomeres; lower face elongate, $0.7 \mathrm{x}$ as broad as high, centrally smooth (Fig. 6), sculptured near the basis of scapus and laterally near the margin eyes, with two shallow furrows from the median area to up, presence of median carina; head with gena long, posterior ocellus separated from eye by $0.6 \mathrm{x}$ its own maximum diameter. Distance from tegula to head $0.8 \mathrm{x}$ the distance from tegula to hind margin of propodeum, scutellum convex, mesopleurum smooth and polished, ventrally with fine and scattered hairs, propodeum smooth and polished with scattered hairs, with lateral longitudinal carina present only posteriorly, submetapleural carina absent. Fore wing with cu-a interstitial to base of Rs \& M, 2 rs-m about $0.15 \mathrm{x}$ as long as abcissa of $\mathrm{M}$ between $2 \mathrm{rs}-\mathrm{m}$ and $2 \mathrm{~m}$-cu, vein $3 \mathrm{rs}-\mathrm{m}$ absent. Hind wing with abscissa of $\mathrm{Cu} 1$ meeting cu-a more or less equidistant between $\mathrm{M}$ and $1 \mathrm{~A}$ (Fig.7). Hind leg with tibia plus tarsus $0.5 \mathrm{x}$ the fore wing length. Tergite I $1.4 \mathrm{x}$ as long as posteriorly broad, with lateral carina present only anteriorly; sternite I with an apically acute, thorn-like ventral projection (Fig. 8), tergite II 1.7x and tergite III about $1.2 \mathrm{x}$ as long as posteriorly broad. Tergites I-III smooth with scattered hairs around of the tergites. Ovipositor 1.2x as long as hind tibia.

Head black, mouth parts pale yellow except the tip of mandible, antenna dark brown. Mesosoma yellow; metasoma with tergite I blackish with laterally margins pale yellow, tergites II-IV brownish with lateral anterior margin and centrally with a broad shallowly v-shaped pale yellow mark anteriorly (Fig. 9). Sternite I smooth, pale yellow; II - VI white and coreaceous. Ovipositor blackish, sheaths black. First pair of legs yellow, second pair yellow with tarsomeres slightly dusky, hind leg black, with base of coxa, trochantelus yellowish, tibial spurs yellow. Fore wing hyaline, pterostigma brownish.
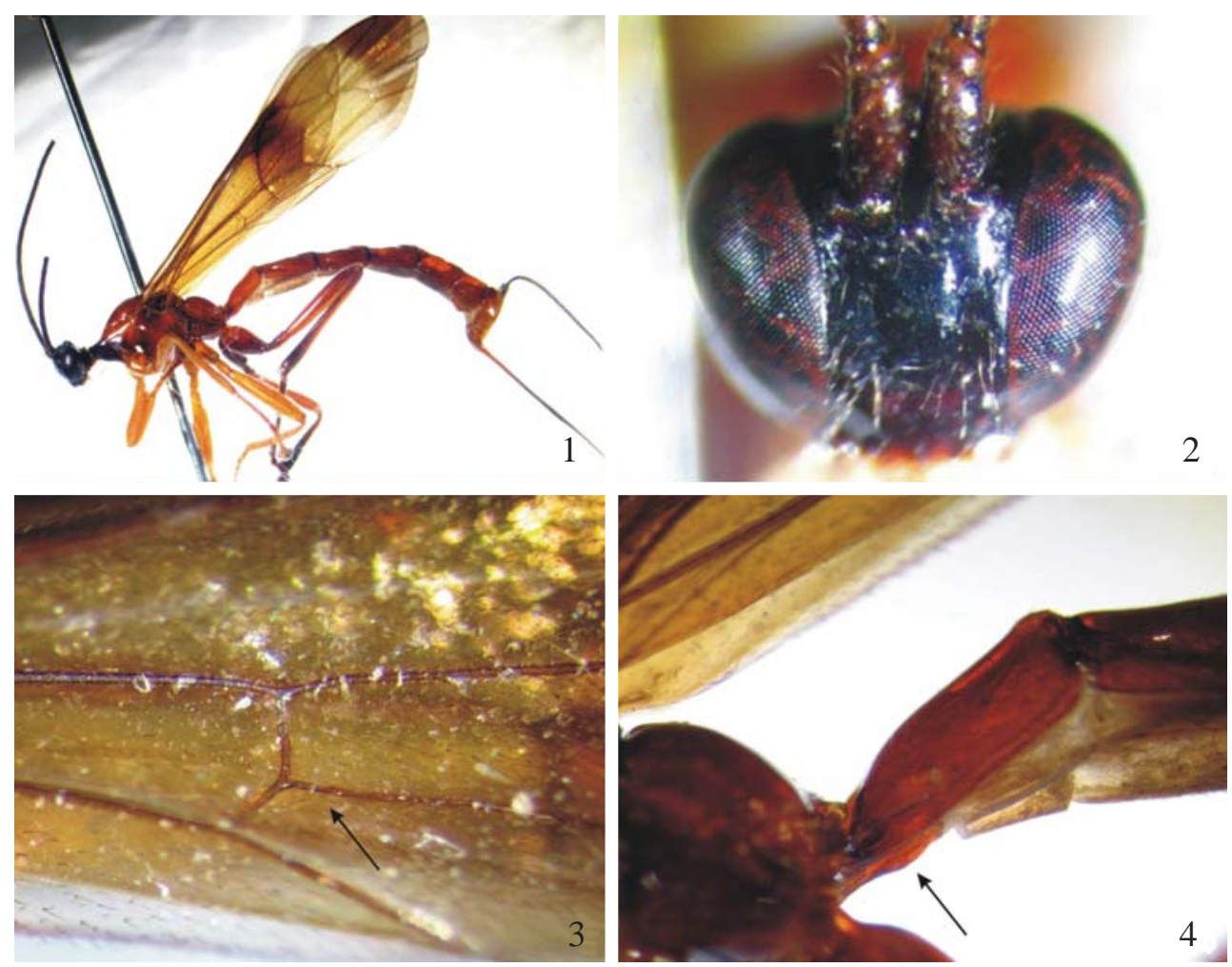

Figs. 1-4. Hymenoepimecis silvanae sp. nov. 1, Habitus; 2, Head (frontal view); 3, Hind wing venation; 4, Sternite I. 

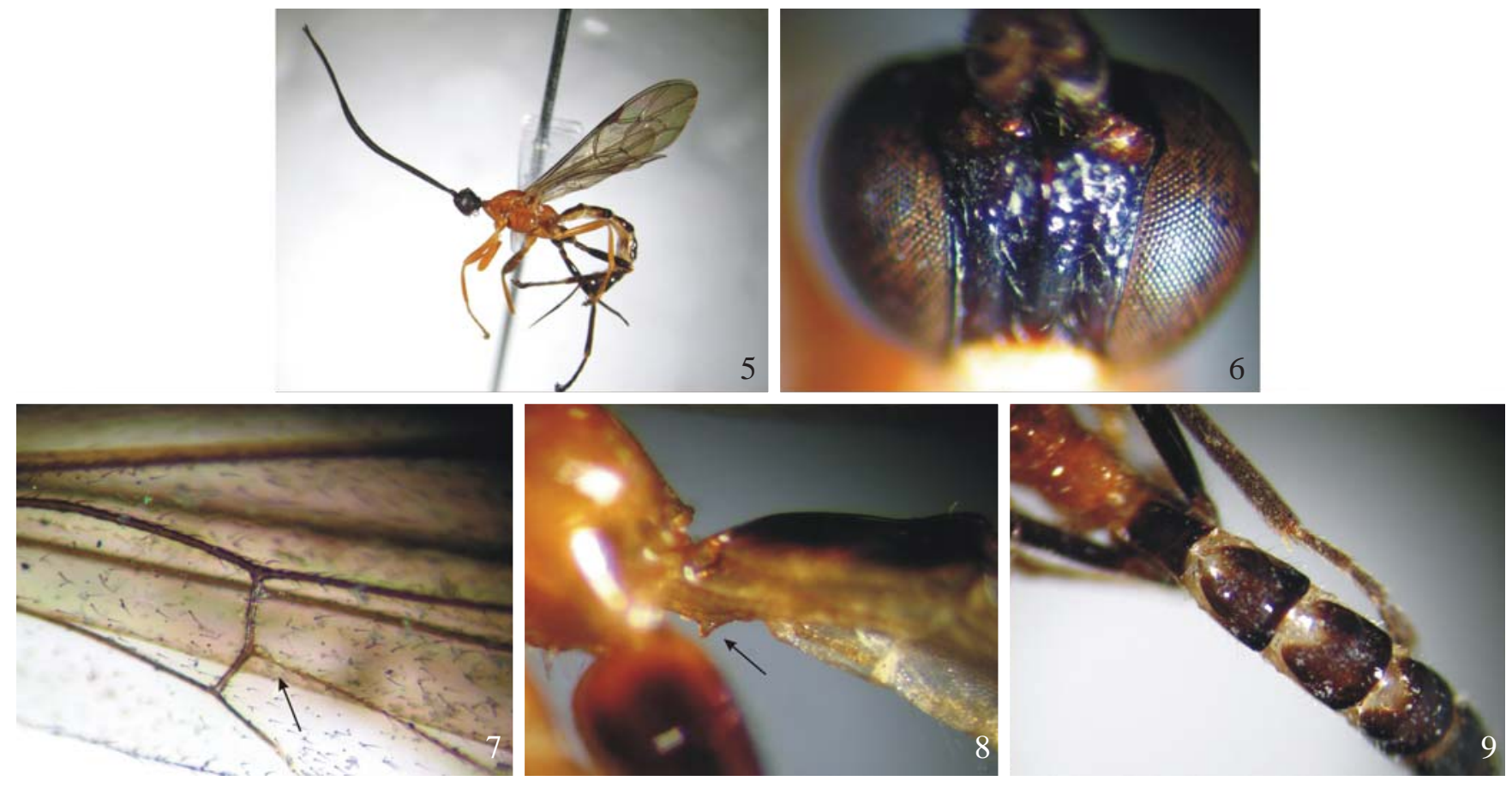

Figs. 5-9. Hymenoepimecis jordanensis sp. nov. 5, Habitus; 6, Head (frontal view); 7, Hind wing venation; 8, Sternite I; 9, metasoma.

Male: Unknown

Etymology: The specific name refers to type locality of this species, Campos do Jordão in São Paulo State, Brazil.

Hymenoepimecis jordanensis sp.nov. closely resembles $H$. atriceps (Cresson, 1865) in having the wings hyaline. The metasoma color is dull ferrugineous in $H$. atriceps and mostly blackish in $H$. jordanensis sp.nov. The legs are mostly pale yellow in H. atriceps; in H. jordanensis sp.nov the hind leg is mostly black.

\section{Hymenoepimecis veranii sp. nov.} (Figs. 10-13)

Material. - Holotype, ㅇ (DCBU), "[Brazil] State of São Paulo, Campos do Jordão, 23.XI to 10.XII.2001, $900 \mathrm{~m}$ altitude, Malaise trap, S. A. G. Gomes col."

Holotype, q, (Fig. 10). Length: $15 \mathrm{~mm}$. Fore wing: $12 \mathrm{~mm}$. Antenna broken, with 31 antennomeres, lower face subquadrate, about 1.0x as broad as high, centrally smooth (Fig. 11), sculptured near the basis of scapus, slightly convex with two shallow furrows from the median area to up, presence of a short median carina only at $1 / 3$ apical of face; head with gena long, posterior ocellus separated from eye by 0.6 times its own maximum diameter. Distance from tegula to head is about $0.8 \mathrm{x}$ the distance from tegula to hind margin of propodeum, scutellum convex, mesopleurum smooth and polished with ventral parts with fine and scattered hairs, propodeum and metapleurum smooth and polished with scattered hairs, submetapleural carina absent. Fore wing with cu-a interstitial to base of Rs \& M, 2 rs-m about $0.5 \mathrm{x}$ as long as the abcissa of $\mathrm{M}$ between $2 \mathrm{rs}-\mathrm{m}$ and $2 \mathrm{~m}$-cu, vein $3 \mathrm{r}$-s absent. Hind wing with distal abscissa of $\mathrm{Cu} 1$ meeting cu-a closer to 1A (Fig.12). Hind leg with tibia 0.3 $x$ the fore wing. Tergite I 3.0x as long as posteriorly broad, with two short lateral carinae present only anteriorly; sternite I with a slight rounded swelling posteriorly ( Fig. 13), tergite II 1.6x and tergite III 1.2x as long as posteriorly broad. Tergites II-V smooth and with scattered hairs around of the tergite. Ovipositor 1.6x as long as hind tibia.

Mesosoma and metasoma mostly reddish brown. Head, ocelli, scapus, pedicel and base of first flagellomere black, tip of mandible and most of flagellum dark brown. Apical margin of clypeus, mandible, except the tip, and palpi yellow. Prosternum black, pronotum with anterior and lateral parts infuscate. Fore and mid legs yellow, mid coxa reddish, two last tarsomeres blackish; hind legs reddish with tarsomeres blackish. Sternite I reddish and smooth; II - VI light brown and coreaceous. Ovipositor reddish, sheaths black. Wings all fuscous, veins at proximal half black and at apical half light brown, pterostigma yellow.

Male: Unknown

Etymology: This species honors José Roberto Verani, our colleague for his efforts at the Programa de Pós-graduação em Ecologia e Recursos Naturais (Universidade Federal de São Carlos, São Paulo, Brasil).

Hymenoepimecis veranii sp. nov. as H. cameroni Townes, 1966 have wing uniformily fuscous, but the pterostigma is yellow in $H$. veranii sp. nov. and fuscous in $H$. cameroni. Differing in color; $H$. veranii sp. nov. is mostly reddish brown and $H$. cameroni, rufo-testaceous with black marks. 

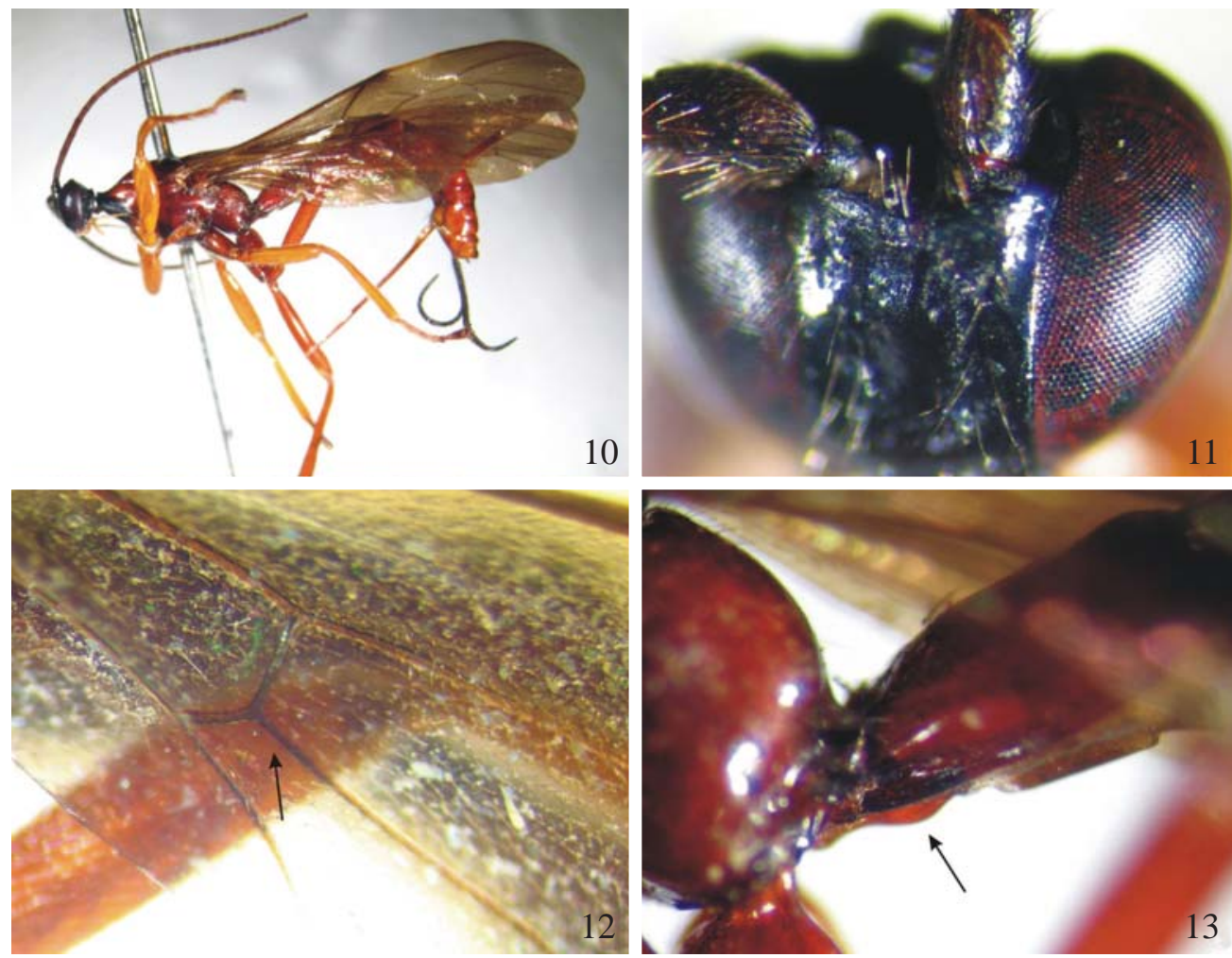

Figs.10-13. Hymenoepimecis veranii sp. nov. 10, Habitus; 11, Head (frontal view); 12, Hind wing venation; 13, Sternite I.

Acknowledgments. We were supported financially by Instituto Nacional de Ciência e Tecnologia dos Hymenoptera Parasitóides da Região Sudeste Brasileira (HYMPAR/Sudeste - CNPq/FAPESP/CAPES), CAPES (research grants to A. P. S. Loffredo), Fundação de Amparo à Pesquisa do Estado de São Paulo (proc. 07/50141-9), and CNPq (grant to A. M. Penteado-Dias).

\section{REFERENCES}

Gauld, I. D. 1991. The Ichneumonidae of Costa Rica, 1. Memoirs of the American Entomological Institute 47: 1-589.

Gauld, I. D. \& J. Dubois. 2006. Phylogeny of the Polysphincta group of genera (Hymenoptera: Ichneumonidae; Pimplinae): a taxonomic revision of spider ectoparasitoids. Systematic Entomology 31: $529-564$. 